\title{
Aortic root replacement with a novel decellularized cryopreserved aortic homograft: Postoperative immunoreactivity and early results
}

\author{
Kenton J. Zehr, MD, ${ }^{a}$ Marineh Yagubyan, MD, ${ }^{a}$ Heidi M. Connolly, MD, ${ }^{b}$ Susan M. Nelson, LPN, ${ }^{a}$ and
} Hartzell V. Schaff, MD ${ }^{\mathrm{a}}$

From the Divisions of Cardiovascular Surgery $^{\mathrm{a}}$ and Cardiology, ${ }^{\mathrm{b}}$ Mayo Clinic, Rochester, Minn.

Received for publication Nov 18, 2004; revisions received Feb 25, 2005; accepted for publication March 23, 2005.

Address for reprints: Kenton J. Zehr, MD, Division of Cardiovascular Surgery, Mayo Clinic, 200 First St SW, Rochester, MN 55905 (E-mail: zehr.kenton@mayo.edu).

J Thorac Cardiovasc Surg 2005;130:1010-5

$0022-5223 / \$ 30.00$

Copyright (C) 2005 by The American Association for Thoracic Surgery

doi:10.1016/j.jtcvs.2005.03.044
Objective: Novel antigen-reduction SynerGraft technology (CryoLife Inc, Kennesaw, Ga) reduces the cellular components of a cadaver homograft with an enzymatic and washing process, leaving the extracellular matrix intact. We report the immunoreactivity (positive panel reactive antibody assay) and early operative results of the CryoLife SynerGraft aortic valve conduit homograft.

Methods: Twenty-two patients (age $53 \pm 14$ years, range 31-80 years) from April 2002 to July 2003 underwent aortic root replacement with a CryoLife SynerGraft aortic valve conduit homograft (CryoLife Inc, Kennesaw, Ga) for congenital or acquired aortic valve disease, aortic aneurysm with aortic valve disease, or native or prosthetic aortic valve endocarditis. Baseline percentage positive panel reactive antibody results were negative $(<10 \%)$ for all and were assessed at 1 month, 3 months, and 1-year. Homograft function was evaluated by echocardiography.

Results: Early mortality was $0 \%$. Two late deaths at 1 postoperative year were unrelated to homograft function. At 1 postoperative month, panel reactive antibody results were negative in 20 patients (91\%). At 3 months, 19 of 22 patients (86\%) had negative results, including 1 with previous positive results. At 1 year, 19 of 20 patients (95\%) had negative results, including 2 of the 3 with previous positive results. The mean aortic valve gradients were $12 \pm 8 \mathrm{~mm} \mathrm{Hg}(\mathrm{n}=21)$ at discharge and $11 \pm 7 \mathrm{~mm} \mathrm{Hg}(\mathrm{n}=18)$ at 1 year. At a mean follow-up of $30.3 \pm 5.2$ months, the mean gradient was $8.8 \pm 6.3 \mathrm{~mm} \mathrm{Hg}$.

Conclusion: The SynerGraft decellularization technology successfully removed antigens from an aortic valve homograft conduit. Aortic root reconstruction with the CryoLife SynerGraft aortic valve homograft resulted in low transvalvular gradients, similar to those seen with standard cryopreserved homografts. These early results suggest an advancement in homograft technology. The low panel reactive antibody response may enhance durability by eliminating immune complex-mediated reaction against the homograft. The lack of allosensitization in patients who may require organ transplantation in the future is an added benefit.

$\mathrm{A}$ ortic and pulmonary valve conduit homografts are associated with low transvalvular gradients and nearly normal exercise hemodynamics. ${ }^{1-5}$ This favorable hemodynamic profile, the lack of need for anticoagulation, and the low incidence of endocarditis, make these tissue reconstructions appealing for young, active adults, patients with contraindications to anticoagulation, and patients with endocarditis. In the aortic position, homografts have a significant structural deterioration curve beginning at 10 years, with few implants lasting as long 20 years postimplantation. ${ }^{6,7}$ In the pulmonary position, graft stenosis can prevent long-term durability. ${ }^{8}$ A persistent immunoreactivity against donor antigens has been implicated. ${ }^{9,10}$ Early calcification and stenosis from an intense inflammatory reaction may 


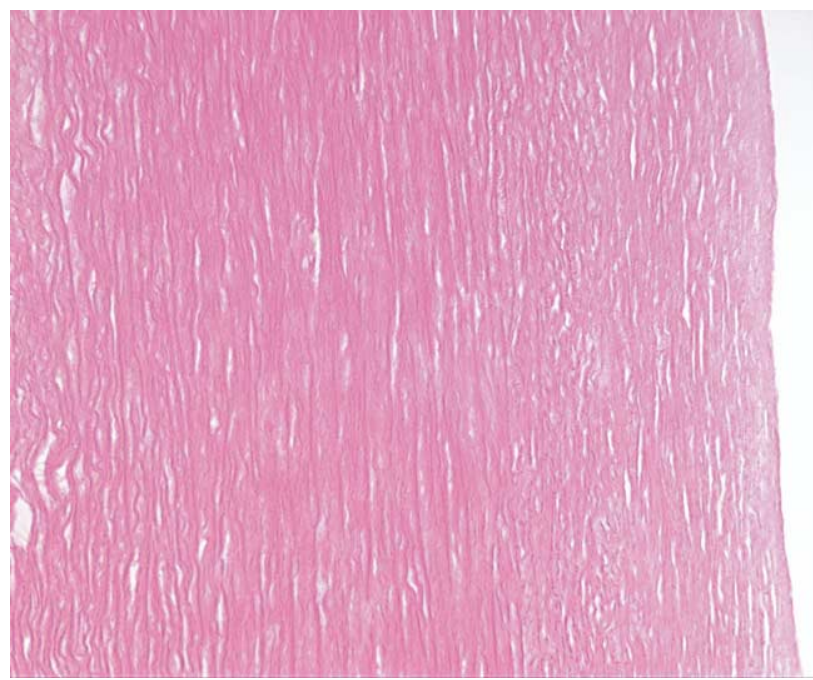

Figure 1. Photomicrograph of aortic wall of decellularized cryopreserved aortic homograft. Note nearly complete accellularity of tissue with maintenance of extracellular matrix (original magnification $20 \times$, hematoxylin and eosin).

be manifestations of this immune response. Early structural failure has been shown to be more prevalent in younger patients, perhaps because of a more aggressive immune response. ${ }^{6}$

In an attempt to reduce the antigenic response, decellularization processes have been introduced for cryopreserved tissue. ${ }^{11}$ Experimental and clinical experience with this decellularization process has been gained with porcine vena cava porcine tissue, ${ }^{12}$ porcine aortic ${ }^{13}$ and pulmonary valve

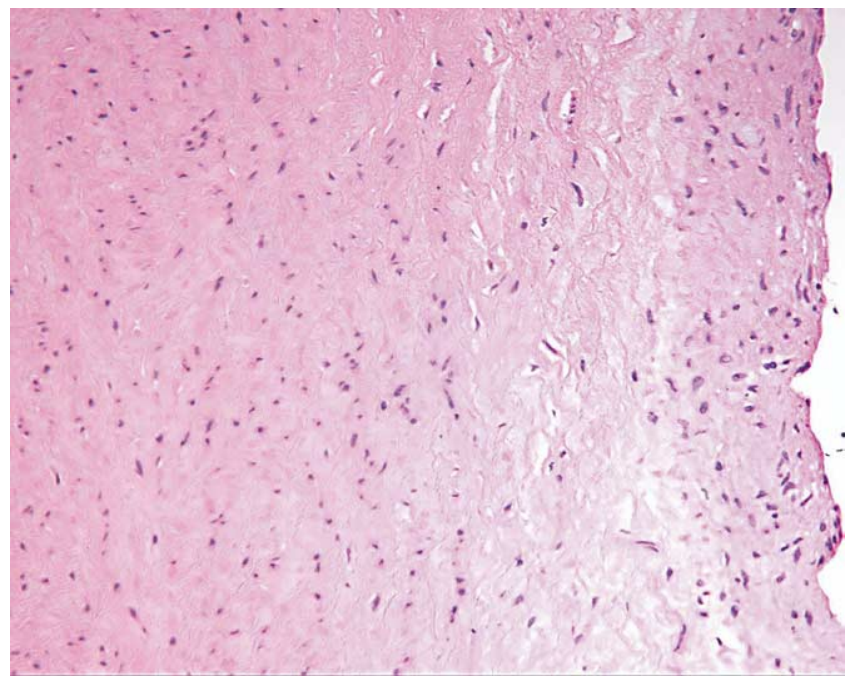

Figure 2. Photomicrograph of aortic wall of standard cryopreserved aortic homograft. Note presence of cellularity of tissue (original magnification $20 \times$, hematoxylin and eosin).

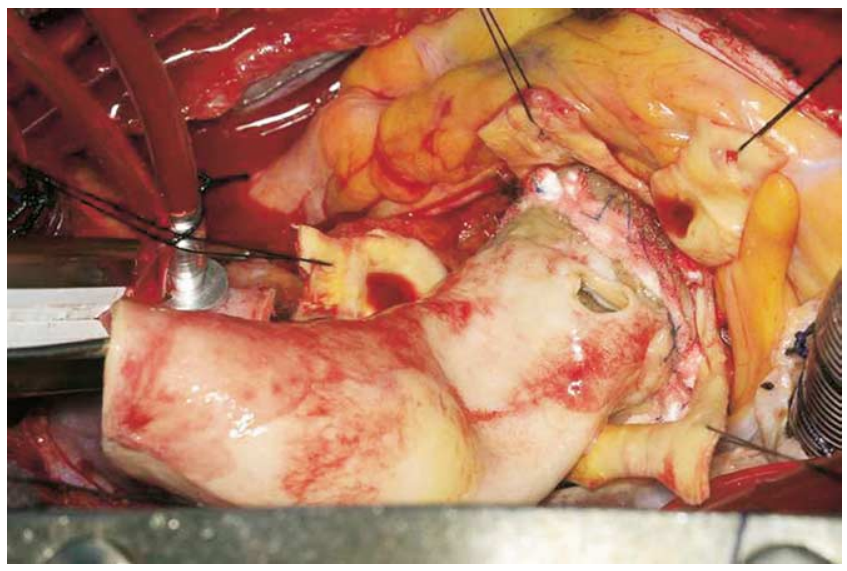

Figure 3. Decellularized cryopreserved aortic homograft during aortic root replacement.

conduits, ovine pulmonary valve conduits, ${ }^{14}$ and, subsequently, human femoral vein ${ }^{15}$ and human pulmonary valve conduits. ${ }^{11,16}$ All have proved to be minimally immunoreactive. There has also been experimental evidence that the decellularized matrix becomes populated with functional recipient cells. ${ }^{11,14}$

Until this study, it has not been definitively shown whether application of this decellularization process to thicker, bulkier, more robust human aortic valve conduits would result in the absence of a persistent humoral response. We sought to assess the immunoreactivity and early hemodynamic results of decellularized cryopreserved aortic valve conduits after aortic root reconstruction. Persistent lack of immunoreactivity theoretically could result in increased durability and increased chance of recipient recellularization. An added benefit would be the lack of allosensitization in patients who might require organ transplantation in the future.

\section{Material and Methods \\ Valve Treatment}

Aortic valve conduits were treated with a proprietary decellularization process (SynerGraft technology, CryoLife, Inc, Kennesaw, $\mathrm{Ga}$ ). The steps include cell lysis in hypotonic solution, enzymatic digestion of nucleic acids, and washout in isotonic, neutral buffer. The valves were then cryopreserved with dimethyl sulfoxide and stored in liquid nitrogen until implantation.

\section{Patients and Surgical Procedure}

Twenty-two patients (age $53 \pm 14$ years, 18 male, 4 female, age range 31-80 years) from April 2002 through July 2003 underwent aortic root replacement with a CryoLife SynerGraft aortic valve conduit homograft. Eight patients had congenital unicuspid or bicuspid aortic valve disease, 6 had acquired tricuspid aortic valve stenosis, 6 had an ascending aortic aneurysm with aortic valve disease, and 1 each had native and prosthetic aortic valve endo- 
carditis. All implants were done as freestanding aortic root replacements with reimplantation of the coronary ostia as buttons. Microscopic analysis of representative SynerGraft aortic tissue samples revealed nearly complete conduit accellularity (Figure 1) compared to standard cryopreserved aortic homografts (Figure 2). The gross appearance of the homografts appeared similar to standard cryopreserved homografts (Figure 3). The Mayo Clinic Internal Review Board approved and monitored this prospective protocol.

\section{Panel Reactive Antibody Testing}

Patient allosensitization was quantified by panel reactive antibody (PRA) assay. Peripheral blood samples were obtained before the operation and at 1 month, 3 months, and 1 year after the operation. Testing was performed by the Mayo Clinic Laboratories in accordance with the American Society for Histocompatibility and Immunogenetics laboratory protocol. ${ }^{17}$ An antiglobulin-mediated complement-dependent cytotoxicity assay on a frozen 50-cell panel was used to determine the presence and spectrum of antibody. A positive cell result was defined as an assay which resulted in greater than $50 \%$ cytotoxicity relative to negative control serum samples. The percentage positive PRA reported is the percentage of reactive cells on the panel. A PRA greater than $10 \%$ was considered to be a positive antibody determination. Baseline PRA were results were negative $(<10 \%$ PRA) for all patients.

\section{Echocardiography}

Transthoracic echocardiography was performed before the operation, at discharge, at 1 postoperative year and at latest follow-up. Intraoperative transesophageal echocardiography was performed in all cases.

\section{Results}

There were no in-hospital deaths. There were two late deaths at 1 postoperative year. Both deaths were unrelated to the homograft; 1 was of congestive heart failure secondary to severe cardiomyopathy related to long-standing aortic regurgitation before the operation, and 1 was of sepsis resulting from lower extremity diabetic gangrene. Unfortunately, these valve conduits could not be obtained for pathologic analysis. The deaths occurred before the 1-year PRA assay.

At 1 month after the operation, PRA results were negative in 20 of 22 patients $(91 \%)$. Two patients (9\%) had PRA percentages of $48 \%$ and $79 \%$. At 3 months, PRA results were negative in 19 of 22 patients $(86 \%)$, including 1 with a previous positive result. Three patients had positive PRA percentages $(11 \%, 21 \%$, and $61 \%)$. At 1 year, 19 of 20 (95\%) patients had negative results, including 2 patients with previous positive results. The remaining patient with a positive result had a PRA percentage of $16 \%$. There was no statistical correlation between blood product transfusion and positive PRA result. Twelve patients required postoperative blood transfusions. The blood products were not leukocyte depleted or irradiated. Only 2 of these patients had positive PRA results.
The mean aortic valve gradients were $12 \pm 8 \mathrm{~mm} \mathrm{Hg}$ $(\mathrm{n}=21)$ at discharge and $11 \pm 7 \mathrm{~mm} \mathrm{Hg}(\mathrm{n}=18)$ at 1 postoperative year (difference not significant). At a mean follow-up of $30.3 \pm 5.2$ months, the mean gradient was 8.8 $\pm 6.3 \mathrm{~mm} \mathrm{Hg}$. The postoperative maximal aortic root diameters were $33.25 \pm 3.8 \mathrm{~mm}$ on discharge echocardiography and $32.6 \pm 3.2 \mathrm{~mm}$ at 1-year echocardiography (difference not significant). No patients had more than trivial aortic valve regurgitation. There were no adverse events of thromboembolism or endocarditis. No patients received anticoagulation during follow-up.

\section{Discussion}

The most significant finding of this study is that antigens can be successfully removed from aortic valve conduit homografts, resulting in essentially no presence of antibody at 1 postoperative year. Although there were no side-by-side control subjects, there is ample evidence in the literature that traditionally prepared cryopreserved allograft tissue incites a broad, strong, and persistent humoral response to donor HLA antigens. Welters and colleagues ${ }^{18}$ found greater than $10 \%$ positive PRA results in 31 of 35 heart valve homograft recipients $(89 \%)$. Among the patients with positive results, 24 (77\%) had donor-specific HLA class I antibodies develop. Antibody titers were followed longitudinally in 8 patients with greater than 50\% PRA. Maximal titers were found at 6 months, and 5 patients had elevated titers at 1 year. Benedetto and associates ${ }^{19}$ studied 20 consecutive patients who received a cryopreserved vein homograft fistula for hemodialysis. Mean PRA assay values were $84.1 \%$ (median $96.5 \%$ ) at a mean of 3.1 postoperative months. They concluded that these traditionally cryopreserved allografts should not be used in potential kidney transplant candidates because of the significant allosensitization incurred. Piatosa and colleagues ${ }^{20}$ found that 12 of 14 patients had positive PRA results as long as 3 months after homograft heart valve implantation. IgG anti-HLA antibodies in the serum were antidonor specific; 6 patients had anticlass I antigens and 6 patients had class II antigens.

The clinical relevance of the immune response is not clear. Evidence suggests that it does play a role in homograft failure. In our patients, echocardiography at 30 months' mean follow-up showed no evidence of aortic wall calcifications and also showed normal cusps. Further follow-up is needed, however, because calcification rarely occurs so quickly after implantation. Koolbergen and associates $^{21}$ studied 40 explanted homografts implanted from 14 days to 16 years. They found a persistent low-grade inflammatory response but did not find conclusive data supporting graft failure caused by immune-mediated injury. A few reports have documented a significant immune response associated with homograft failure. Welters and colleagues ${ }^{18}$ reported on a patient with early allograft failure thought to 
be related to the development of extremely high donorspecific anti-HLA antibody titers (1:8000). Carr-White and coworkers ${ }^{8}$ reported on 4 patients who were reoperated on for rapidly progressive pulmonary homograft stenosis after a Ross procedure. Significant postoperative inflammatory reaction was diagnosed both macroscopically and microscopically. Indirect evidence implicating the immune response in reducing allograft durability is provided by the relatively more rapid deterioration of standard cryopreserved tissue in children and young adults. It is also interesting to observe that conduit calcification and valve deterioration is rarely seen in immune-suppressed patients after cardiac transplantation. Logically, it would follow that tissue typing might increase durability of homograft tissue. This has been difficult to prove. Bechtel and associates ${ }^{5}$ tissue typed pulmonary homografts implanted during the Ross procedure in 26 patients for HLA-A, HLA-B, and HLA-DR. Fifty-four percent of patients had anti-HLA class I antibody positive results at a mean follow-up of $15 \pm 6$ months. A significant transhomograft pressure gradient increase was observed during this time, but there was no demonstrable relationship with the degree of histocompatibility. In a larger series of 47 patients (57\% positive PRA), the same group ${ }^{4}$ observed no differences in transpulmonary pressure gradient or degree of pulmonary regurgitation according to the presence or absence of anti-HLA antibodies.

There has been considerable experimental and clinical background leading to our decision to place decellularized cryopreserved aortic homografts in the aortic position. In a porcine superior vena cava replacement model, decellularized cryopreserved vena cava homografts were completely repopulated by the recipient with an endothelial lining. ${ }^{10}$ Stains for T-cell surface antigen, CD4, and CD8 yielded negative results. Neoendothelial cells stained for factor VIII. Smooth muscle cells in arteriole walls stained for smooth muscle actin, and cells scattered in the adventitia stained for procollagen type I. Elkins and coworkers ${ }^{14}$ reported recellularization of both porcine and ovine decellularized cryopreserved pulmonary valve conduits after implantation into both the aortic and pulmonary positions in an ovine model. After 11 months, leaflet explants had no detectable inflammatory cells and were as much as $80 \%$ repopulated with fibrocytes and smooth muscle cells staining for procollagen type I and smooth muscle actin, respectively. The recellularization of the cusps appeared to progress from the conduit wall, either from the adjacent myocardium or from neovascularization of the implant. Cusp free margin repopulation did not occur before the midportion of the cusp was recellularized. A functional recolonization process was also found in SynerGraft-treated bovine ureters implanted as arteriovenous fistulas in a canine model. ${ }^{22}$ After 24 weeks, the matrixes were fully colonized, with procollagen synthesis demonstrated. Im- plant incorporation into the surrounding subcutaneous tissue was noted. Elongated cells staining for smooth muscle actin were noted. In all these experimental models, the decellularized tissue maintained functional integrity. Grauss and associates ${ }^{23}$ studied a similar detergent-enzymatic (ribonuclease and deoxyribonuclease) extraction method on rat aortic valve conduits. Transplanted decellularized conduits were completely acellular, with minimal damage to the extracellular matrix. Functionally, the leaflets remained normal, unlike cellular allogeneic control grafts, which became deformed, swollen, and acellular, with major changes in the extracellular matrix. Oei and colleagues ${ }^{24}$ determined that the cryopreservation process alone minimally affected the extracellular matrix but left abundant HLA class II-positive endothelial cells.

Clinically, the lack of antigenicity of decellularized tissue has been encouraging. Decellularized cryopreserved human femoral veins implanted for arteriovenous fistula to be used for renal dialysis access resulted in no measurable reactive antibody, as contrasted with the broad immunoreactivity incited by nondecellularized femoral veins. ${ }^{15}$ The lack of immunoreactivity has also been shown in a large series of patients receiving a decellularized cryopreserved pulmonary homograft for pulmonary valve conduit replacements in the Ross procedure. ${ }^{16}$ Eighty-eight percent of patients (43/49) had no humoral immune response at 3 months. Bechtel and colleagues ${ }^{25}$ found no anti-class I HLA antibodies in 24 patients receiving a decellularized cryopreserved pulmonary valve conduit, in contrast to $66 \%$ of 22 patients receiving a traditional cryopreserved pulmonary homograft. In a pediatric population, Hawkins and associates $^{26}$ demonstrated significantly lower levels of class I and class II HLA antibody formation at 1, 3, and 12 months than with standard cryopreserved allografts.

The lack of antigenicity of decellularized matrixes appears to vary when transplanted in a xenograft model. When decellularized porcine conduits are placed in an ovine model, $80 \%$ of the matrixes are repopulated with host fibroblasts. ${ }^{14,27}$ In contrast, Simon and coworkers ${ }^{28}$ have reported on early failure of SynerGraft-treated porcine conduits implanted into children. Early explants had a severe foreign-body reaction, with infiltration of neutrophils and macrophages and lymphocytes at late explantation. There was no cell repopulation of the porcine matrix. The fibroblasts appeared to be unable to penetrate the matrix and instead became encapsulated. Goldstein and colleagues ${ }^{27}$ have reported on 3 patients ( 3 with aortic valve conduits and 2 with pulmonary valve conduits) with good early functional results with decellularized porcine conduits. These results suggest caution regarding application of decellularized xenograft matrixes to the human situation, particularly in children. 
One of the concerns of applying a decellularization process to aortic valve conduits is their significant bulkiness and thickness in relation to the other tissues. This could have implications on the completeness and uniformity of antigen removal. Of some concern, in an early experience with decellularized cryopreserved aortic valve conduit homografts reported in part by Elkins, ${ }^{29} 25 \%$ of 22 patients had a humoral response. These were the first clinically implanted SynerGraft-treated allografts. It is known that the decellularization process can be variably complete, which may have played a role in this early experience. In contrast, the patients in our study have shown a remarkable lack of immunoreactivity of the decellularized cryopreserved aortic valve conduits with complete follow-up to 1 year.

Before this study, previous clinical applications were directed toward small-caliber vessels (femoral vein), which are subjected to systemic pressure but relatively low wall tension because of the diameter of the vessel, and pulmonary valve conduits, which are subjected to relatively low pulmonary artery pressures. Biomechanical evaluations of tensile strength, modulus extensibility, stress relaxation, and static creep have been analyzed in SynerGraft allograft aortic valves, pulmonary valves, femoral arteries, and femoral veins and compared with those of standard cryopreserved tissue. All parameters measured were within the ranges usually observed for fibrillar connective tissue matrixes. No differences were noted relative to standard cryopreserved tissue. Ultrastructural integrity of the SynerGraft tissue matrix, as determined by thermal denaturation temperature, has been found to be equivalent to that of standard cryopreserved tissue. The aortic valve conduits used in this study had a similar gross appearance to standard homografts (Figure 3). The tissue handling attributes and the ability to hold sutures were subjectively identical to those of standard cryopreserved tissue. We observed no short-term durability issues. The valve conduits held up in the setting of systemic circulatory hemodynamics to a mean of 30 months. The valve gradients were nearly identical to those at hospital discharge, and no valves had more than trivial regurgitation. Bechtel and colleagues ${ }^{25}$ showed similar hemodynamic results in a report of their initial experience with decellularized cryopreserved pulmonary homografts in the pulmonary position in 17 patients. At 6 months of follow-up, the SynerGraft group had similar transhomograft pressure gradients and minimal loss in measured orifice area, as opposed to a significant rise in peak and mean gradients and loss of orifice area in a matched control group of 17 patients undergoing the Ross procedure with a standard cryopreserved pulmonary homograft. The future may be one step beyond decellularization. In the unique clinical experience reported by Dohmen and colleagues, ${ }^{30}$ a decellularized pulmonary homograft was seeded with viable autologous vascular endothelial cells and implanted in the pulmonary position in a patient undergoing a Ross procedure. Seeded cellular viability was proved before implantation, and conduit hemodynamics were normal at 1-year follow-up, with no evidence of calcification.

This report of our initial experience with implantation of decellularized SynerGraft human aortic valve conduits in the aortic position confirms their lack of immunoreactivity. Early hemodynamic data appear equivalent to those of standard homografts. Proof of cellular repopulation by donor cells must await long-term follow-up showing lack of calcification, improved durability, and evidence of donor cells in tissue explants. If the conceptual ideas prove valid, decellularized homografts may represent a significant advancement in homograft technology. The lack of allosensitization clearly has ramifications for patients destined for any future organ transplantation, and decellularized homografts should be considered as an alternative to standard homografts in these patients.

\section{References}

1. Aklog L, Carr-White GS, Birks EJ, Yacoub MH. Pulmonary autograft versus aortic homograft for aortic valve replacement: interim results from a prospective randomized trial. J Heart Valve Dis. 2000;9:17689.

2. Wang A, Jaggers J, Ungerleider RM, Lim CS, Ryan T. Exercise echocardiographic comparison of pulmonary autograft and aortic homograft replacements for aortic valve disease in adults. $J$ Heart Valve Dis. 2003;12:202-8

3. Laforest I, Dumesnil JG, Briand M, Cartier PC, Pibarot P. Hemodynamic performance at rest and during exercise after aortic valve replacement: comparison of pulmonary autografts versus aortic homografts. Circulation. 2002;106:157-62.

4. Bechtel JF, Bartels C, Schmidtke C, Skibba W, Muller-Steinhardt M, Kluter H, et al. Anti-HLA class I antibodies and pulmonary homograft function after the Ross procedure. Ann Thorac Surg. 2001;71:2003-7.

5. Bechtel JF, Bartels C, Schmidtke C, Skibba W, Muller-Steinhardt M, Kluter $\mathrm{H}$, et al. Does histocompatibility affect homograft valve function after the Ross procedure? Circulation. 2001;104(12 Suppl 1): I25-8.

6. Lund O, Chandrasekaran V, Grocott-Mason R, Elwidaa H, Mazhar R, Khaghani A, et al. Primary aortic valve replacement with allografts over twenty-five years: valve-related and procedure-related determinants of outcome. J Thorac Cardiovasc Surg. 1999:117:77-90.

7. O'Brien MF, Harrocks S, Stafford EG, Gardner MA, Pohlner PG, Tesar PJ, et al. The homograft aortic valve: a 29-year, $99.3 \%$ follow up of 1,022 valve replacements. J Heart Valve Dis. 2001;10:334-45.

8. Carr-White GS, Kilner PJ, Hon JK, Rutledge T, Edwards S, Burman $\mathrm{ED}$, et al. Incidence, location, pathology and significance of pulmonary homograft stenosis after the Ross operation. Circulation. 2001;104(12 Suppl 1):I16-20.

9. Smith JD, Hornick PI, Rasmi N, Rose ML, Yacoub MH. Effect of HLA mismatching and antibody status on "homovital" aortic valve homograft performance. Ann Thorac Surg. 1998;66(6 Suppl):S212-5.

10. Dignan R, O'Brien M, Hogan P, Passage J, Stephens F, Thornton A, et al. Influence of HLA matching and associated factors on aortic valve homograft function. J Heart Valve Dis. 2000;9:504-11.

11. Elkins RC, Dawson PE, Goldstein S, Walsh SP, Black KS. Decellularized human valve allografts. Ann Thorac Surg. 2001;71(5 Suppl): S428-32.

12. Wells W, Malas M, Baker CJ, Quardt SM, Barr ML. Depopulated vena caval homograft: a new venous conduit. J Thorac Cardiovasc Surg. 2003;126:498-503.

13. O'Brien MF, Goldstein S, Walsh S, Black KS, Elkins R, Clarke D. The SynerGraft valve: a new acellular) nonglutaraldehyde-fixed) tissue 
heart valve for autologous recellularization first experimental studies before clinical implantation. Semin Thorac Cardiovasc Surg. 1999;11:194-200.

14. Elkins RC, Goldstein S, Hewitt CW, Walsh SP, Dawson PE, Ollerenshaw JD, et al. Recellularization of heart valve grafts by a process of adaptive remodeling. Semin Thorac Cardiovasc Surg. 2001;13:87-92.

15. Madden R, Lipkowitz G, Benedetto B, Kurbanov A, Miller M, Bow L. Decellularized cadaver vein allografts used for hemodialysis access do not cause allosensitization or preclude kidney transplantation. Am $J$ Kidney Dis. 2002;40:1240-3.

16. Elkins RC, Lane MM, Capps SB, McCue C, Dawson PE. Humoral immune response to allograft valve tissue pretreated with an antigen reduction process. Semin Thorac Cardiovasc Surg. 2001;13:82-6.

17. Zachary AA, Teresi GA. American Society for Histocompatibility and Immunogenetics laboratory manual. 2nd ed. Lenexa (KS): American Society for Histocompatibility Immunogenetics; 1990. p. 1-716.

18. Welters MJ, Oei FB, Witvliet MD, Vaessen LM, Cromme-Dijkhuis $\mathrm{AH}$, Bogers AJ, et al. A broad and strong humoral immune response to donor HLA after implantation of cryopreserved human heart valve allografts. Hum Immunol. 2002;63:1019-25.

19. Benedetto B, Lipkowitz G, Madden R, Kurbanov A, Hull D, Miller M, et al. Use of cryopreserved cadaveric vein allograft for hemodialysis access precludes kidney transplantation because of allosensitization. J Vasc Surg. 2001;34:139-42.

20. Piatosa B, Birbach M, Fedorowicz M, Maruszewski B. Presence of IgG anti-HLA antibodies in fourteen patients after cryopreserved allogenic heart valve implantation. Transplant Proc. 2002;34:643-4.

21. Koolbergen DR, Hazekamp MG, de Heer E, Bruggemans EF, Huysmans HA, Dion RA, et al. The pathology of fresh and cryopreserved homograft heart valves: an analysis of forty explanted homograft valves. J Thorac Cardiovasc Surg. 2002;124:689-97.
22. Matsuura JH, Black KS, Levitt AB, Rosenthal D, Wellons ED, Fallon MT, et al. Cellular remodeling of depopulated bovine ureter used as an arteriovenous graft in the canine model. J Am Coll Surg. 2004; 1998:778-83.

23. Grauss RW, Hazekamp MG, van Vliet S, Gittenberger-de Groot AC, DeRuiter MC. Decellularization of rat aortic valve allografts reduces leaflet destruction and extracellular matrix remodeling. J Thorac Cardiovasc Surg. 2004;128:155-6.

24. Oei FB, Stegmann AP, van der Ham F, Zondervan PE, Vaessen LM, Baan CC, et al. The presence of immune stimulatory cells in fresh and cryopreserved donor aortic and pulmonary valve allografts. J Heart Valve Dis. 2002;11:315-25.

25. Bechtel JF, Muller-Steinhardt M, Schmidtke C, Brunswik A, Stierle U, Sievers HH. Evaluation of the decellularized pulmonary valve homograft (SynerGraft). J Heart Valve Dis. 2003;12:739-40.

26. Hawkins JA, Hillman ND, Lambert LM, Jones J, Di Russo GB, Profaizer T, et al. Immunogenicity of decellularized cryopreserved allografts in pediatric cardiac surgery: comparison with standard cryopreserved allografts. J Thorac Cardiovasc Surg. 2003;126:24753.

27. Goldstein S, Clarke DR, Walsh SP, Black KS, O'Brien MF. Transpecies heart valve transplant: advanced studies of a bioengineered xenoautograft. Ann Thorac Surg. 2000;70:1962-9.

28. Simon P, Kasimir MT, Seebacher G, Weigel G, Ullrich R, SalzerMuhar U, et al. Early failure of the tissue engineered porcine heart valve SYNERGRAFT in pediatric patients. Eur J Cardiothorac Surg. 2003;23:1002-6.

29. Elkins RC. Is tissue-engineered heart valve replacement clinically applicable? Curr Cardiol Rep. 2003;5:125-8.

30. Dohmen PM, Lembcke A, Hotz H, Kivelitz D, Konert WF. Ross operation with a tissue-engineered heart valve. Ann Thorac Surg. 2002;74:1438-42. 